\title{
Baited technique improves censuses of cryptic fish in complex habitats
}

\author{
Bryce D. Stewart*, Joanne S. Beukers
}

James Cook University, Townsville, Queensland 4810, Australia

\begin{abstract}
Many fish species are cryptic by nature or show a negative response to divers. This may make traditional censusing techniques difficult to perform and the results obtained using these methods may be inaccurate. This problem will be exacerbated in complex habitats, such as those found on coral reefs, because the cryptic species present will be even more difficult to locate and identify. Predation studies on coral reefs have been especially hampered by this problem because many predatory species are cryptic and so it has been difficult to obtain reliable abundance estimates. This study tested a visual census technique that used bait to bring cryptic predatory fish into view. Results from this census were then compared to those from a traditional survey using belt transects, and to a patch reef tagging study where all individuals of 3 key species were located. The baited technique produced significantly higher density estimates for 3 of the 4 most abundant cryptic species. The patch reef experiment demonstrated that the baited technique accounted for 85 to $96 \%$ of fish present. Censuses without bait observed only 40 to $61 \%$ of fish present. For mobile species, on the other hand, the baited census appeared to overestimate abundance, due to movement of fish into the census area. We therefore recommend combining baited censuses of sedentary cryptic species with traditional censuses of mobile species to gain an accurate picture of piscivorous reef fish communities. Using this approach at Lizard Island on the Great Barrier Reef, the proportion of cryptic piscivores in the community was found to be almost double that which would have otherwise been observed. We also found considerable spatial variation in the abundance and distribution of piscivorous fish. These patterns would have been quite different had the survey been based on belt transects alone. Previous studies using belt transects may therefore have underestimated the importance of cryptic piscivorous species in communities of coral reef fish.
\end{abstract}

KEY WORDS: Visual censuses · Baited censuses · Cryptic species · Piscivorous fish · Predation · Coral reefs $\cdot$ Community structure $\cdot$ Spatial variation

\section{INTRODUCTION}

Accurate estimates of abundance are essential for understanding the ecology of fish populations and communities. In general, fishes on coral and rocky reefs can be censused either visually or destructively. Visual censuses (eg. belt transects and point censuses) are the most commonly used as they are rapid, cause little disturbance and can produce accurate measures of relative density (Sale \& Douglas 1981). The major disadvantage of visual censuses, however, is that they tend to underestimate the abundance of species that are small, cryptic or wary of divers (Brock 1954, Brock

\footnotetext{
- Present address: Port Erin Marine Laboratory, University of Liverpool, Port Erin, Isle of Man IM9 6JA, United Kingdom. E-mail: brycebs@liverpool.ac.uk
}

1982, Martin 1994). This is particularly the case in highly complex habitats such as coral reefs. Destructive censuses involving the use of chemicals such as rotenone (Brock 1982) or explosives (Williams \& Hatcher 1983), are less favoured than visual censuses as they vary in effectiveness for different species, are difficult to quantify and cause considerable disturbance to the community in question (Thresher \& Gunn 1986). This makes destructive sampling non-repeatable and therefore unsuitable for examining temporal variation at a particular site. On the other hand, destructive sampling is generally thought to be the best technique for estimating the abundance of small and cryptic fish. A third alternative is to estimate abundance by tagging all fish in an area so that they can be individually recognised (Thresher \& Gunn 1986). This technique can produce very accurate estimates but has 
rarely been used as it is an extremely labour intensive and time consuming process.

Predation appears to play an important role in determining the structure of populations and communities of coral reef fish (Hixon 1991, Jones 1991, Caley et al. 1996). Several recent studies have shown a link between the abundance of piscivorous fish and the mortality of prey (e.g. Caley 1993, Connell 1996, Hixon \& Carr 1997). Censuses of spatial and temporal variation in predator abundance may therefore provide an insight into predation pressure in coral reef fish communities. Despite the recent interest in predation on coral reefs, however, only a few studies (e.g. Williams \& Hatcher 1983, Newman et al. 1997, Connell \& Kingsford 1998) have examined the abundance and distribution of piscivorous fish. As many piscivorous species, particularly of the family Serranidae, are cryptic by nature (Randall et al. 1990), the abundance, and therefore trophic importance of these fish, may also have been underestimated in previous studies using standard visual census techniques.

The main aim of this study was to develop an accurate, non-destructive protocol for censusing both cryptic and mobile species of predatory reef fish. To this end we tested a census technique that consisted of a variation on the point census method whereby bait was used to attract cryptic species into view. A similar method to this has been used previously by Gotshall (1987) in temperate waters, although he did not examine the accuracy of the technique or compare it to other methods. We examined the effectiveness of the baited technique in 2 ways: first, by comparison with the results from a survey of quadrats (divided into belt transects) at the same sites. This comparison, however, may have been confounded by net immigration of fish into the baited census area. To overcome this problem an experiment was performed on isolated patch reefs which involved tagging all individuals of 3 key cryptic species. This provided an absolute abundance against which counts from the 2 techniques could be compared.

The secondary aim of this study was to use results from the above censuses to examine the distribution, abundance and species composition of piscivorous fish in the waters around Lizard Island on the Great Barrier Reef, Australia. Lizard Island has been used as a site for numerous ecological studies examining the effects of recruitment and post-settlement mortality on populations of coral reef fish (e.g. Aldenhoven 1986, Meekan 1988, Caley 1995, Beukers 1996). On experimental reefs, Caley (1995) found piscivore abundance and mortality of prey to be higher at Lizard Island than One Tree Island, in the southern Great Barrier Reef. It was hoped that the availability of information on predation pressure in natural communities at Lizard
Island may shed some light on the results of these previous studies.

\section{METHODS}

Identification of piscivorous species. A total of 48 species of fish from 8 families were included in the censuses as piscivores (see Table 1). Determination of these species as piscivores was based on published dietary analyses. Species were then further divided into confirmed and opportunistic piscivores. Confirmed piscivores were those species known to include fish as a regular part of their diet. Some of these species may also consume a proportion of other types of prey such as crustaceans. Opportunistic piscivores were those species that normally consume other types of prey but may occasionally prey on fish. Species were also classified as being either cryptic and relatively sedentary or mobile, again on the basis of published information (see Table 1) and personal observations. Mobile species were expected to be attracted to the baited censuses from some distance. If there was any possibility of the identity of 2 species being confused, they were pooled for analysis (see Table 1). Nocturnally active piscivores (e.g. Holocentridae) were not included in the study, as all censuses were conducted in daylight hours. Highly active pelagic fish such as the family Carangidae were also not counted, as such fish are not adequately sampled by belt transects (Thresher \& Gunn 1986). Moray eels (Muraenidae) were not included in the censuses either, as while being cryptic they are also very mobile and therefore would not be accurately sampled by either method we planned to use.

Baited point censuses. Baited point censuses (BPC) of piscivorous fish were conducted in December 1994 and January 1995 at 9 sites around Lizard Island $\left(14^{\circ} 40^{\prime} \mathrm{S}, 145^{\circ} 28^{\prime} \mathrm{E}\right)$ on the Great Barrier Reef, Australia (Fig. 1). These sites represented 3 zones of exposure to the prevailing weather conditions: exposed ( 3 sites), sheltered ( 3 sites) and lagoonal ( 3 sites). To carry out BPC, fluorescent tape was used to mark out 10 points around the circumference of a $5 \mathrm{~m}$ radius circle (area $78.54 \mathrm{~m}^{2}$ ), generally centred on the slope of the reef. A mesh bag containing 4 pilchards was placed in the middle of the circle. At the start of each observational period the pilchards were pulverised with a hammer. This bait was intended to bring into view cryptic species whose abundance may have otherwise have been underestimated. All piscivorous fish individuals observed during a $15 \mathrm{~min}$ search of this circle were counted. Observers were careful not to count the same individual more than once. Six censuses were conducted at each site, a total of 54 overall. 
Table 1. List of species censused as piscivores at Lizard Island

\begin{tabular}{|c|c|c|c|c|}
\hline Species censused & $\begin{array}{l}\text { Maximum size } \\
\text { (total length, } \mathrm{cm} \text { ) }\end{array}$ & $\begin{array}{l}\text { Behaviour } \\
\text { (mobility) }\end{array}$ & $\begin{array}{l}\text { Piscivore } \\
\text { category }\end{array}$ & Sources \\
\hline \multicolumn{5}{|l|}{ Synodontidae (lizardfishes) } \\
\hline Synodus spp. & 28 & Mobile & Confirmed & 1,6 \\
\hline \multicolumn{5}{|l|}{ Scorpaenidae (scorpionfishes) } \\
\hline Pterois volitans & 38 & Cryptic & Confirmed & 4,6 \\
\hline \multicolumn{5}{|l|}{ Serranidae (groupers) } \\
\hline Anyperodon leucogrammicus & 52 & Cryptic & Confirmed & 5,6 \\
\hline Cephalopholis boenak & 24 & Cryptic & Confirmed & 2,6 \\
\hline Cephalopholis cyanostigma & 35 & Cryptic & Confirmed & 2,6 \\
\hline Cephalopholis microprion & 23 & Cryptic & Confirmed & 2,6 \\
\hline Cephalopholis urodeta & 27 & Cryptic & Confirmed & 5,6 \\
\hline Cromileptes altivelis & 66 & Cryptic & Confirmed & 6 \\
\hline Epinephelus caeruleopunctatus & 60 & Cryptic & Confirmed & 6 \\
\hline Epinephelus corallicola & 31 & Cryptic & Confirmed & 6 \\
\hline Epinephelus fasciatus & 35 & Cryptic & Confirmed & 4,6 \\
\hline Epinephelus howlandi & 45 & Cryptic & Confirmed & 6 \\
\hline Epinephelus spp. & 35 & Cryptic & Confirmed & 4,6 \\
\hline Epinephelus ongus & 40 & Mobile & Confirmed & 6 \\
\hline Plectropomus leopardus & 75 & Mobile & Confirmed & 8,9 \\
\hline \multicolumn{5}{|l|}{ Pseudochromidae (dottybacks) } \\
\hline Psuedochromis fuscus & 9 & Cryptic & Confirmed & 2,6 \\
\hline \multicolumn{5}{|l|}{ Lutjanidae (snappers) } \\
\hline Lutjanus bohar & 75 & Mobile & Confirmed & 6,10 \\
\hline Lutjanus carponotatus & 40 & Mobile & Confirmed & 6,7 \\
\hline Lutjanus fulviflamma & 35 & Mobile & Confirmed & 6,7 \\
\hline Lutjanus fulvus & 40 & Mobile & Confirmed & 6,10 \\
\hline Lutjanus gibbus & 50 & Mobile & Confirmed & 6,11 \\
\hline Lutjanus monostigma & 50 & Mobile & Confirmed & 6,11 \\
\hline Lutjanus quinquelineatus & 38 & Mobile & Confirmed & 6,12 \\
\hline Lutjanus russeli & 45 & Mobile & Confirmed & \\
\hline Lutjanus vitta & 40 & Mobile & Confirmed & 5,6 \\
\hline \multicolumn{5}{|l|}{ Lethrinidae (emperors) } \\
\hline Lethrinus harak & 60 & Mobile & Confirmed & 6 \\
\hline Lethrinus nebulosus & 86 & Mobile & Confirmed & 6 \\
\hline Lethrinus obsoletus & 40 & Mobile & Confirmed & 6 \\
\hline Monotaxis grandoculis & 60 & Mobile & Confirmed & 6 \\
\hline \multicolumn{5}{|l|}{ Cirrhitidae (hawkfishes) } \\
\hline Paracirrhites forsteri & 22 & Cryptic & Confirmed & 1,6 \\
\hline \multicolumn{5}{|l|}{ Pinguipedidae (sandperches) } \\
\hline Parapercis hexopthalma & 23 & Mobile & Opportunistic & 6 \\
\hline \multicolumn{5}{|l|}{ Labridae (wrasses) } \\
\hline Bodianus axillaris & 20 & Mobile & Opportunistic & 6 \\
\hline Bodianus mesothorax & 20 & Mobile & Opportunistic & 6 \\
\hline Cheilinus chlorourus & 36 & Mobile & Confirmed & 6,1 \\
\hline Oxycheilinus digrammus & 30 & Mobile & Confirmed & $6,7,13$ \\
\hline Cheilinus trilobatus & 40 & Mobile & Confirmed & 6 \\
\hline Cheilinus undulatus & 230 & Mobile & Confirmed & 6 \\
\hline Choerodon fasciatus & 30 & Mobile & Opportunistic & 6 \\
\hline Epibulus insidiator & 35 & Mobile & Confirmed & $1,6,13$ \\
\hline Halichoeres prosopeion & 13 & Mobile & Opportunistic & 6 \\
\hline Thalassoma amblycephalum & 16 & Mobile & Opportunistic & 6 \\
\hline Thalassoma hardwicke & 18 & Mobile & Opportunistic & 6 \\
\hline Thalassoma jansenii & 20 & Mobile & Opportunistic & 6 \\
\hline Thalassoma lunare & 25 & Mobile & Opportunistic & $2,6,7$ \\
\hline Thalassoma lutescens & 25 & Mobile & Opportunistic & 6 \\
\hline \multicolumn{5}{|c|}{$\begin{array}{l}\text { ancludes Saurida gracilis, Synodus dermatogenys and Synodus variegatus } \\
\text { bIncludes Epinephelus merra and E. quoyanus }\end{array}$} \\
\hline \multicolumn{5}{|c|}{$\begin{array}{l}\text { Sources: (1) Parrish et al. (1986); (2) Martin (1994); (3) Sweatman (1984); (4) Harmelin-Vivien \& Bouchon (1976); (5) Hiatt \& } \\
\text { Strasburg (1960); (6) Randall et al. (1990); (7) Connell (1998); (8) Kingsford (1992); (9) St John (1995); (10) Miles (1963); } \\
\text { (11) Randall \& Brock (1960); (12) Sweatman (1993); (13) Gottleib (1992) }\end{array}$} \\
\hline
\end{tabular}




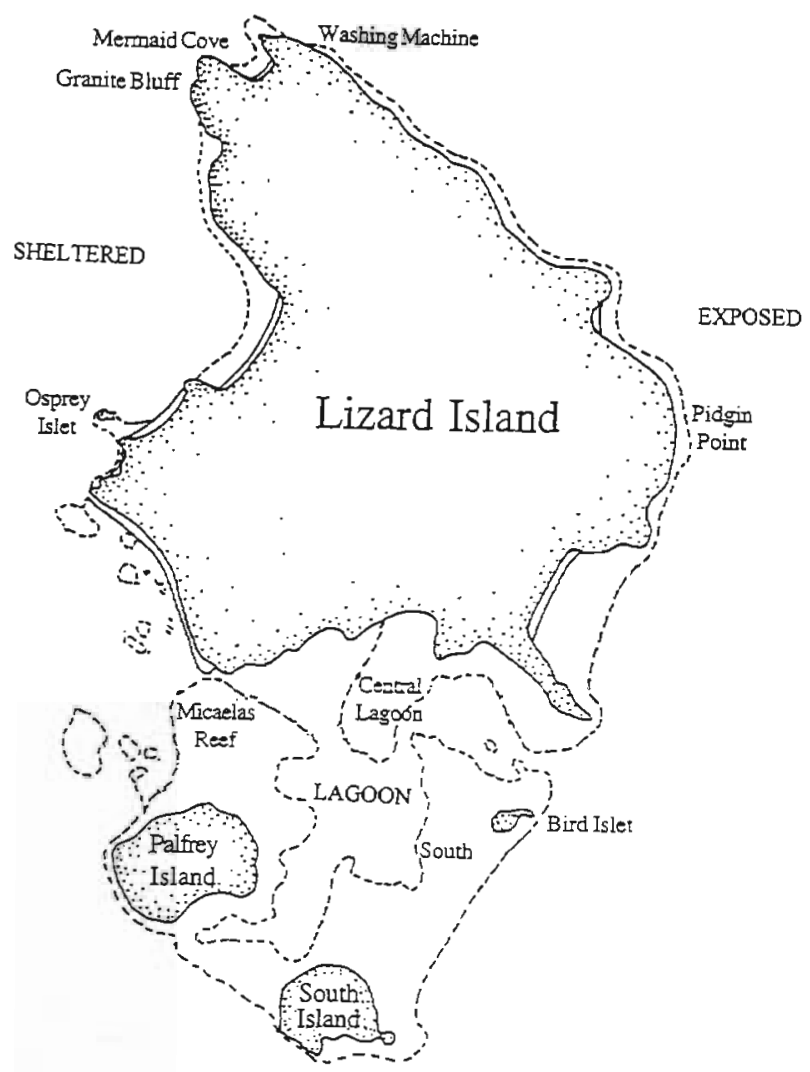

Fig. 1. Map of Lizard island, Great Barrier Reef, Australia, showing the study sites. Note the 3 zones of exposure (exposed, sheltered and lagoon) and the 3 sites within each zone

Quadrat censuses. Quadrat censuses (QC) of piscivorous fish species were conducted in January 1995 at the same 9 sites around Lizard Island as above (see Fig. 1). At each site an $18 \times 30 \mathrm{~m}$ quadrat was set up using measuring tapes, parallel to the reef edge and centred on the slope (as for the BPC). With additional measuring tapes, quadrats were then divided into 6 belt transects, each $30 \mathrm{~m}$ long and $3 \mathrm{~m}$ wide (area $90 \mathrm{~m}^{2}$ ). Each tape had been marked every $3 \mathrm{~m}$ to effectively divide the quadrat into a grid consisting of sixty $3 \times 3 \mathrm{~m}$ squares.

To carry out fish counts a diver swam up and back each transect in turn. Mobile species were generally counted on the way out and cryptic species on the return. All habitat was intensively searched, including any caves or ledges, which were examined with a flashlight. Approximately $15 \mathrm{~min}$ was spent counting fish in each transect (a total of $90 \mathrm{~min}$ in each quadrat). Any piscivorous fish observed during the $\mathrm{QC}$ were plotted on the grid in the position at which they were first seen. Mapping fish positions in this fashion improved the accuracy of our fish counts in several ways. First, it helped ensure that individual fish were not counted more than once, which is a potential risk when censusing adjacent transects. Second, it enabled flighty species to be plotted on the grid well ahead of the diver, hence reducing the likelihood that their numbers would be underestimated.

As each transect in the QC covered a similar area to each point census, and $15 \mathrm{~min}$ was spent conducting each census, this meant that search time per unit area was very similar between the 2 census methods. This allowed density estimates produced by the BPC and $\mathrm{QC}$ to be directly compared.

Patch reef experiment. To examine the relative accuracy of baited and unbaited census techniques, an experiment involving 3 cryptic, piscivorous species of rock-cod, Cephalopholis cyanostigma, C. boenak and C. microprion (Serranidae), was conducted on 6 isolated patch reefs (mean size $165 \mathrm{~m}^{2}$ ) in February 1995. These fish species are known to rarely move between these patch reefs (Stewart 1998) and so were ideal for the study. Initially, a diver counted numbers of the target species seen while swimming around each reef in a spiral-like fashion, starting at the base and working up to the top. All caves and ledges on the reef were again intensively searched with a flashlight. On average, it took approximately $30 \mathrm{~min}$ to census a reef in this way. Within 1 to $3 \mathrm{~d}$ the same reefs were again censused in a similar fashion, but this time 4 crushed pilchards were placed on each reef to attract fish (simulating the baited point census method).

Finally, as part of another study on the same reefs (Stewart 1998), an intensive tag and release program was undertaken over the next $7 \mathrm{~d}$ for the same 3 species of rock-cod. This involved capturing fish underwater with a baited hook and line and tagging individuals with a pair of T-bar anchor tags. After tagging, fish were placed back on the reef within $1 \mathrm{~m}$ of where they were captured. A total of 47 Cephalopholis cyanostigma, 22 C. boenak and 21 C. microprion were tagged in this way. This represented nearly all of the target species present on the reefs and made it possible to identify and count the few untagged individuals that remained. At the conclusion of this exercise we could therefore calculate accurate estimates of absolute density for each species.

Data analysis. Comparison of BPC and QC: All fish densities were converted to the mean number of fish per $100 \mathrm{~m}^{2}$. Data were transformed to $\sqrt{x}+\sqrt{x+1}$ to improve normality and heterogeneity (Underwood 1981). Differences between the $B P C$ and $Q C$ were then examined by a 1-factor ANOVA comparing the total density of piscivores estimated by the 2 methods and by a 2 -factor ANOVA comparing the methods at species level. The 2 fixed factors were census method and species. Differences between densities estimated for each species by the 2 methods were examined by 
Tukey's honestly significant difference (HSD) method (Day \& Quinn 1989). Probabilities of obtaining a significant difference were adjusted according to the number of comparisons made in order to reduce the chance of type 1 errors.

Patch reef experiment: For each patch reef the number of fish counted by both the visual and baited visual censuses was calculated as a percentage of the number determined from the tagging study. These percentages were then averaged for the 6 reefs. This was deemed to represent the accuracy of each technique for measuring the absolute density of each species. Data were then arcsine transformed to allow parametric tests. Differences between the percentage accuracy of the 2 techniques were examined by a 2 -factor ANOVA. The 2 fixed factors were census method and species. The percentage difference between densities of each target species estimated by baited and unbaited census methods was also calculated for both the experiment and the original censuses done on the reef slope (i.e. the $\mathrm{BPC}$ and $\mathrm{QC}$ ). To do this for the original censuses, 6 sites were chosen at random and for each method the censuses at each site were pooled for comparison. Data were again arcsine transformed and compared with a 2 -factor ANOVA (factors as above). This addressed the question of whether or not the differences observed between the 2 census methods in the experiment were representative of differences observed between the $\mathrm{BPC}$ and QC.

Spatial variation in the abundance of piscivorous fish: Patterns of spatial variation in the abundance of piscivorous fish were examined for all families and the 20 most abundant species. Differences between the mean total number of piscivorous fish observed at each site and between zones were also examined. Data were again transformed to or $\sqrt{x}+\sqrt{x+1}$ to $\sqrt{x}$ improve normality and heterogeneity. The significance of differences was tested by 2 -factor nested ANOVA. The 2 factors were zone (fixed) and site nested within zone (random).

\section{RESULTS}

\section{Comparison of BPC and QC}

Overall, the BPC estimated a mean density of 37.37 piscivores $/ 100 \mathrm{~m}^{2}( \pm 2.76 \mathrm{SE})$ at Lizard Island, more than double the number observed in the $\mathrm{QC}$, 18.09 piscivores $/ 100 \mathrm{~m}^{2}( \pm 1.75 \mathrm{SE}$ ) (significant difference; Table 2a). Comparing the 2 techniques at species level showed a significant interaction between census method and species (Table 2b). Post hoc analysis (Table 3) revealed that the BPC produced significantly higher density estimates for 9 of the 12 most abundant species of fish. These included Pseudochromis fuscus, Cephalopholis cyanostigma and $C$. boenak, which were 3 of the 4 most abundant cryptic species. The BPC also produced a higher density estimate for the fourth abundant cryptic species, C. microprion, but this was not significant. For mobile fish the BPC produced significantly higher density estimates for 6 of the 8 most abundant species. These included 4 labrids, Thalassoma Iunare, T. hardwicke, Cheilinus chlorourus and Oxycheilinus digrammus, and also Lutjanus carponatatus and Plectropomus leopardus. The QC produced a significantly higher estimate for only 1 mobile species, Lutjanus quinquelineatus. This result was probably due to several chance encounters with schools of this species during the QC. The total number of species observed, on the other hand, was quite similar for the QC and BPC (38 and 37 species respectively), although 8 species were exclusive to the $\mathrm{QC}$ and 7 species to the BPC. All of these species, however, were in low abundance (see Table 3).

\section{Patch reef experiment}

In the patch reef experiment the baited visual censuses were shown to produce a significantly more accurate measure of absolute density (between 85 and

Table 2. Results of ANOVA comparing the density of (a) total numbers and (b) each species of piscivorous fish estimated by the baited point and quadrat census methods ("indicates significant difference)

\begin{tabular}{|c|c|c|c|c|c|}
\hline Source & SS & df & MS & $F$ & Significance of $F$ \\
\hline \multicolumn{6}{|l|}{ (a) Total numbers } \\
\hline Method & 10042.05 & 1 & 10042.00 & 34.89 & $<0.001^{\circ}$ \\
\hline Error & 30511.31 & 106 & 287.84 & & \\
\hline \multicolumn{6}{|l|}{ (b) Each species } \\
\hline Species & 3148.90 & 44 & 71.57 & 88.21 & $<0.001^{\text {. }}$ \\
\hline Method & 77.72 & 1 & 77.72 & 95.79 & $<0.001^{\circ}$ \\
\hline Species $\times$ Method & 330.50 & 44 & 7.51 & 9.26 & $<0.001^{\circ}$ \\
\hline Error & 3870.14 & 4770 & 0.81 & & \\
\hline
\end{tabular}


Table 3. Density (mean no./100 $\mathrm{m}^{2}$ ) of each piscivorous species estimated by the baited point (BPC) and quadrat (QC) censuses and the results of Tukey's HSD multiple comparison of means. ns: no significant difference. BPC or QC singularly indicates the species was exclusive to that census

\begin{tabular}{|c|c|c|c|c|c|c|}
\hline Species censused & Behaviour & $\mathrm{BPC}$ & $\mathrm{SE}$ & $\mathrm{QC}$ & $\mathrm{SE}$ & Tukey's \\
\hline Thalassoma lunare & Mobile & 15.33 & 1.57 & 6.65 & 0.94 & $\mathrm{BPC}>\mathrm{QC}$ \\
\hline Thalassoma hardwicke & Mobile & 2.45 & 0.31 & 1.38 & 0.36 & $\mathrm{BPC}>\mathrm{QC}$ \\
\hline Thalassoma amblycephalum & Mobile & 2.43 & 1.65 & 0.99 & 0.60 & ns \\
\hline Psuedochromis fuscus & Cryptic & 2.05 & 0.30 & 1.03 & 0.18 & $\mathrm{BPC}>\mathrm{QC}$ \\
\hline Cephalopholis cyanostigma & Cryptic & 1.93 & 0.23 & 0.91 & 0.17 & $\mathrm{BPC}>\mathrm{QC}$ \\
\hline Lutjanus carponotatus & Mobile & 1.65 & 0.21 & 0.06 & 0.03 & $\mathrm{BPC}>\mathrm{QC}$ \\
\hline Thalassoma jansenii & Mobile & 1.56 & 0.32 & 1.09 & 0.39 & ns \\
\hline Cheilinus chlorourus & Mobile & 1.44 & 0.21 & 0.39 & 0.15 & $\mathrm{BPC}>\mathrm{QC}$ \\
\hline Cephalopholis microprion & Cryptic & 1.08 & 0.23 & 0.76 & 0.22 & ns \\
\hline Plectropomus leopardus & Mobile & 0.94 & 0.15 & 0.19 & 0.07 & $\mathrm{BPC}>\mathrm{QC}$ \\
\hline Cephalopholis boenak & Cryptic & 0.90 & 0.21 & 0.23 & 0.06 & $\mathrm{BPC}>\mathrm{QC}$ \\
\hline Oxycheilinus digrammus & Mobile & 0.64 & 0.12 & 0.29 & 0.10 & $\mathrm{BPC}>\mathrm{QC}$ \\
\hline Choerodon fasciatus & Mobile & 0.59 & 0.18 & 0.62 & 0.17 & ns \\
\hline Lutjanus fulviflamma & Mobile & 0.57 & 0.27 & 0.76 & 0.50 & ns \\
\hline Epinephelus spp. & Cryptic & 0.47 & 0.12 & 0.21 & 0.07 & ns \\
\hline Synodus spp. & Mobile & 0.40 & 0.13 & 0.31 & 0.09 & ns \\
\hline Parapercis hexophtalma & Mobile & 0.38 & 0.15 & 0.04 & 0.03 & ns \\
\hline Epinephelus fasciatus & Cryptic & 0.33 & 0.09 & 0.02 & 0.02 & ns \\
\hline Lutjanus bohar & Mobile & 0.33 & 0.12 & 0.02 & 0.02 & ns \\
\hline Cephalopholis urodeta & Cryptic & 0.28 & 0.11 & 0.00 & 0.00 & $\mathrm{BPC}$ \\
\hline Bodianus axillaris & Mobile & 0.26 & 0.08 & 0.25 & 0.09 & $\mathrm{~ns}$ \\
\hline Epibulus insidiator & Mobile & 0.26 & 0.07 & 0.39 & 0.11 & ns \\
\hline Cheilinus trilobatus & Mobile & 0.24 & 0.07 & 0.08 & 0.04 & ns \\
\hline Monotaxis grandoculis & Mobile & 0.17 & 0.07 & 0.16 & 0.06 & ns \\
\hline Lutjanus gibbus & Mobile & 0.12 & 0.05 & 0.02 & 0.02 & ns \\
\hline Paracirrhites forsteri & Cryptic & 0.09 & 0.06 & 0.04 & 0.03 & ns \\
\hline Halichoeres prosopeion & Mobile & 0.09 & 0.05 & 0.00 & 0.00 & $\mathrm{BPC}$ \\
\hline Lutjanus fulvus & Mobile & 0.07 & 0.05 & 0.00 & 0.00 & $\mathrm{BPC}$ \\
\hline Lutjanus quinquelineatus & Mobile & 0.07 & 0.05 & 0.60 & 0.19 & $\mathrm{BPC}<\mathrm{QC}$ \\
\hline Lethrinus nebulosus & Mobile & 0.07 & 0.05 & 0.00 & 0.00 & $\mathrm{BPC}$ \\
\hline Lutjanus monostigma & Mobile & 0.05 & 0.03 & 0.00 & 0.00 & $\mathrm{BPC}$ \\
\hline Cheilinus undulatus & Mobile & 0.05 & 0.03 & 0.04 & 0.03 & NS \\
\hline Epinephelus howlandi & Cryptic & 0.02 & 0.02 & 0.00 & 0.00 & $\mathrm{BPC}$ \\
\hline Lethrinus harak & Mobile & 0.02 & 0.02 & 0.00 & 0.00 & $\mathrm{BPC}$ \\
\hline Bodianus mesothorax & Mobile & 0.02 & 0.02 & 0.16 & 0.06 & ns \\
\hline Thalassoma lutescens & Mobile & 0.02 & 0.02 & 0.04 & 0.03 & ns \\
\hline Pterois volitans & Cryptic & 0.00 & 0.00 & 0.06 & 0.05 & $\mathrm{QC}$ \\
\hline Anyperodon leucogrammicus & Cryptic & 0.00 & 0.00 & 0.02 & 0.02 & QC \\
\hline Cromileptes altivelis & Cryptic & 0.00 & 0.00 & 0.02 & 0.02 & $\mathrm{QC}$ \\
\hline Epinephelus corallicola & Cryptic & 0.00 & 0.00 & 0.02 & 0.02 & $\mathrm{QC}$ \\
\hline Epinephelus ongus & Mobile & 0.00 & 0.00 & 0.02 & 0.02 & $\mathrm{QC}$ \\
\hline Lutjanus russeli & Mobile & 0.00 & 0.00 & 0.16 & 0.07 & $Q C$ \\
\hline Lutjanus vitta & Mobile & 0.00 & 0.00 & 0.02 & 0.02 & $\mathrm{QC}$ \\
\hline Lethrinus obsoletus & Mobile & 0.00 & 0.00 & 0.02 & 0.02 & $\mathrm{QC}$ \\
\hline
\end{tabular}

Table 4. (a) Results of ANOVA examining the accuracy of the visual and baited visual census methods in the patch reef experiment ("significant difference). (b) Results of ANOVA comparing the difference between the visual and baited visual density estimates in the experimental and original censuses

\begin{tabular}{|c|c|c|c|c|c|}
\hline Source & SS & df & MS & $F$ & Significance of $F$ \\
\hline \multicolumn{6}{|c|}{ (a) Visual vs baited visual census method } \\
\hline Species & 0.03 & 2 & 0.01 & 0.12 & 0.890 \\
\hline Method & 4.08 & 1 & 4.08 & 34.03 & $<0.001^{\bullet}$ \\
\hline Species $\times$ Method & 0.49 & 2 & 0.24 & 2.04 & 0.148 \\
\hline Error & 3.60 & 30 & 0.12 & & \\
\hline \multicolumn{6}{|c|}{ (b) Experimental vs original censuses } \\
\hline Species & 0.79 & 2 & 0.40 & 2.61 & 0.090 \\
\hline Census & 0.001 & 1 & 0.001 & 0.007 & 0.933 \\
\hline Species $\times$ Census & 0.02 & 2 & 0.01 & 0.07 & 0.931 \\
\hline Error & 4.56 & 30 & 0.15 & & \\
\hline
\end{tabular}


$96 \%$ ) than the unbaited visual censuses (between 40 and $61 \%$ ), for the 3 species censused (Table $4 a$, Fig. 2a). The general trend was for the unbaited visual census to be least accurate for Cephalopholis boenak but slightly more accurate for C. cyanostigma and C. microprion. These trends appeared to be repeated in the original censuses (Fig. 2b), indicating that for the 3 rock-cod species the patch reef experiment was probably quite representative of what was occurring on the reef slope. The percentage differences between the densities estimated for each species by the 2 techniques in the experiment were not significantly different from those $a b-$ served in the original censuses (Table $4 \mathrm{~b}$ ). In general,

a)

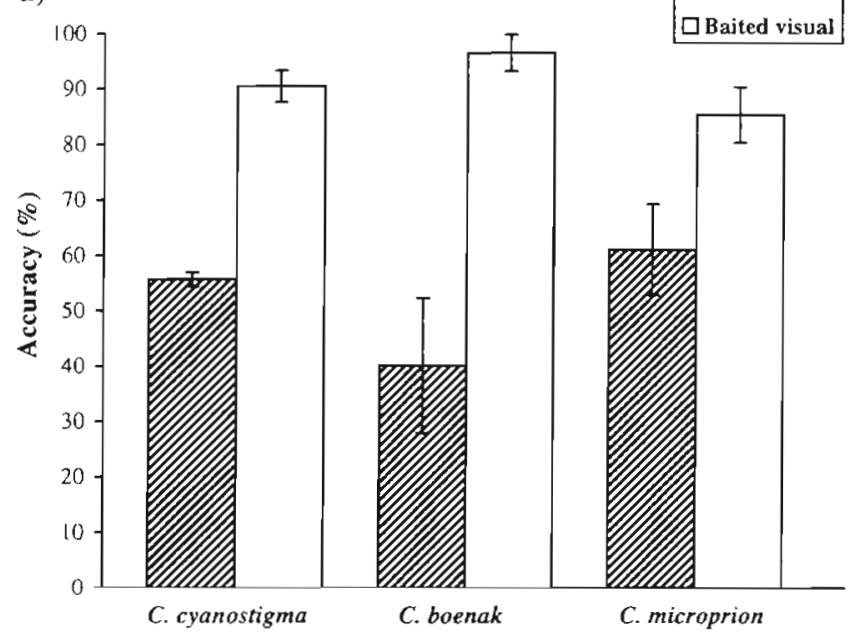

b)
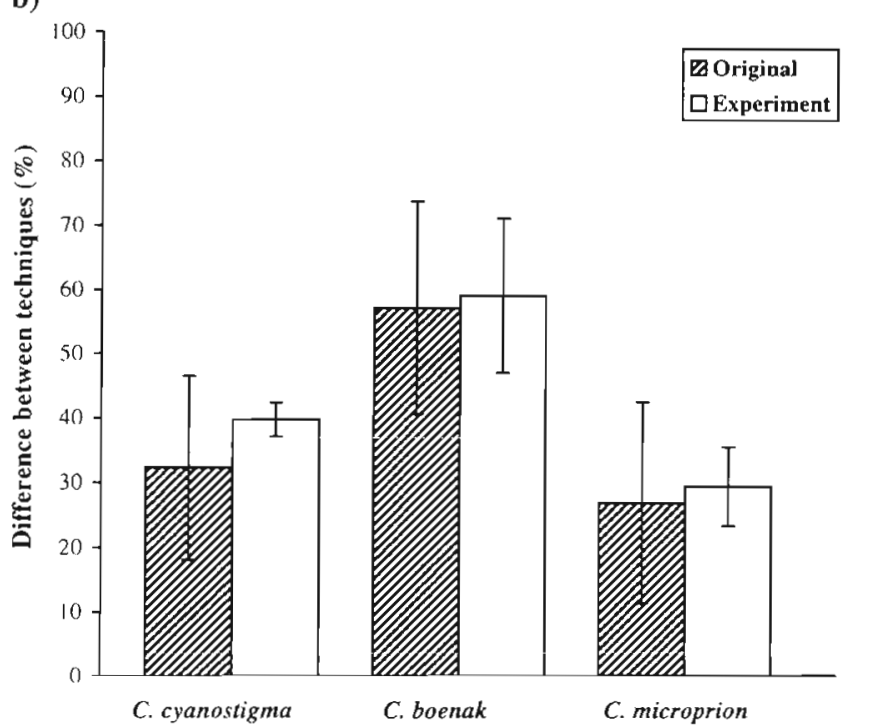

Fig. 2. (a) Percentage accuracy (mean \pm SE) of the visual and baited census techniques for the 3 rock-cod species in the patch reef experiment $(n=6)$. (b) Difference between the 2 techniques (mean percentage $\pm \mathrm{SE}$ of fish not seen without bait) in the original censuses $(n=6)$ and the patch reet experiment $(n=6)$
30 to $55 \%$ of the rock-cods sighted when bait was present were not seen in the unbaited visual censuses.

\section{Community structure of piscivorous fish at Lizard Island}

Based on the comparison between the BPC and the $\mathrm{QC}$ and the results of the patch reef experiment, we decided that sedentary cryptic species were more accurately estimated by the BPC. For the mobile species, on the other hand, personal observations indicated that large numbers of these fish were moving into the census areas during the BPC. The BPC probably over-estimated the abundance of these species and we concluded that the mobile species were more accurately estimated by the $\mathrm{QC}$. We considered that a combination of the BPC density estimates for cryptic species with the $\mathrm{QC}$ density estimates for mobile species would produce the most accurate overall picture of the community structure of piscivorous fish. The use of BPC density estimates for cryptic species almost doubled their representation in the piscivorous fish community from $17.61 \%$ (in the QC) to $32.19 \%$ (in the combined census). When only confirmed piscivores (see Table 1) were considered, cryptic species increased in proportion from 53.37 to $74.56 \%$ of the community. At the family level, with all species included (Fig. 3a), Labridae was most highly represented, followed by Serranidae, Pseudochromidae and Lutjanidae. The 4 other families-Synodontidae, Lethrinidae, Cirrhitidae and Pinguipedidae-made up only a small proportion of the remainder. If the analysis is restricted to confirmed piscivores (Fig. 3b), however, Serranidae becomes the dominant family with Labridae being reduced to the fourth most common family. These patterns can be explained by examining the relative densities of each species censused (Fig. 4). Many of the most abundant species belonged to the genus Thalassoma (Labridae), which are opportunistic feeders that only occasionally prey on fish (Randall et al. 1990). The high abundance of rock-cods (genus: Cephalopholis) largely accounts for Serranidae being the most common family of confirmed piscivores.

\section{Spatial variation in the abundance of piscivorous fish}

Using the combined census (as above) we also examined spatial variation in the abundance of piscivorous fish at Lizard Island. The total number of piscivorous fish belonging to 3 families showed significant variation between zones (Fig. 5, Table 5a). Labrids were more abundant in the exposed zone than the 


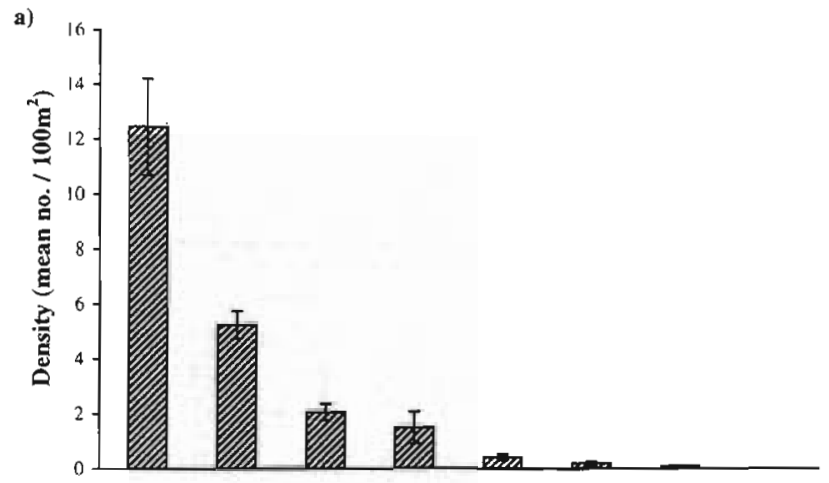

b)

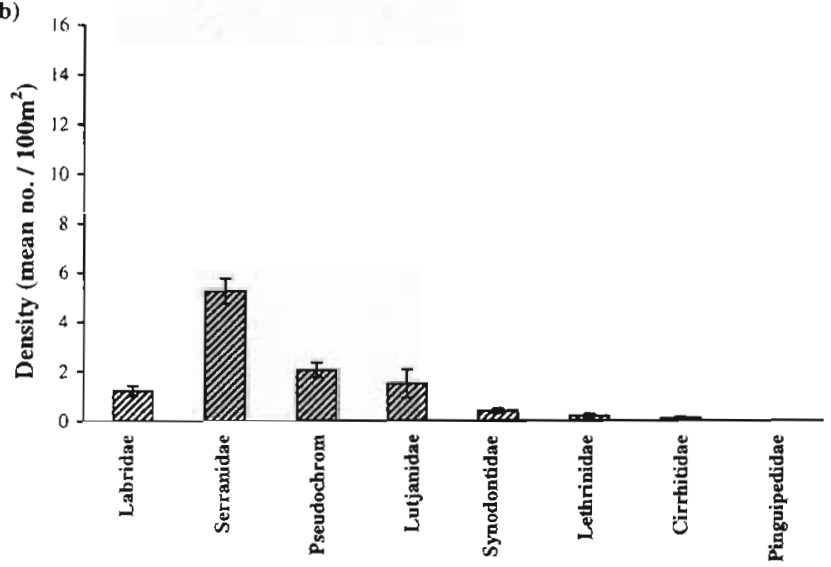

Fig. 3. Density (mean $\pm \mathrm{SE}$ ) of families of piscivorous fish at Lizard Island estimated by the combined census (cryptic species - baited point census; mobile species - quadrat census; $n=54$; (a) all species; (b) confirmed piscivorous only (Pseudochrom $=$ Pseudochromidae) lagoon, while serranids were more abundant in the sheltered zone than the lagoon (Table 5b). Pseudochromids (represented by Pseudochromis fuscus) were more abundant in the sheltered zone than either the exposed zone or the lagoon. Three families Labridae, Serranidae and Lutjanidae-also varied significantly at the site level (Table 5a). These patterns can be further explained by examining patterns of spatial variation for each species (Fig. 6, Table 6a). Four species - Thalassoma lunare, Pseudochromis fuscus (as above), Cephalopholis boenak and Epibulus insidiator-varied significantly at zone level. $T$. lunare was more abundant in the exposed zone than the lagoon, $P$. fuscus and $C$. boenak were more abundant in the sheltered zone than either the exposed zone or the lagoon and $E$. insidiator was more abundant in the lagoon than in either the exposed or sheltered zones (Table 6b). Eleven of the 20 most abundant species also showed significant variation in abundance at site level (Table 6a). Patterns of spatial variation in total numbers of piscivorous fish changed according to which groups were included in the analysis. At the site level there was significant variation in piscivore abundance when both all species and confirmed piscivores only were analysed (Fig. 7, Table 7). Rank order of abundance of piscivores at the 9 sites changed, however, according to the group considered. Patterns of total piscivore abundance were often driven by high abundances of opportunistic predators such as Thalassoma lunare. At zone level there was

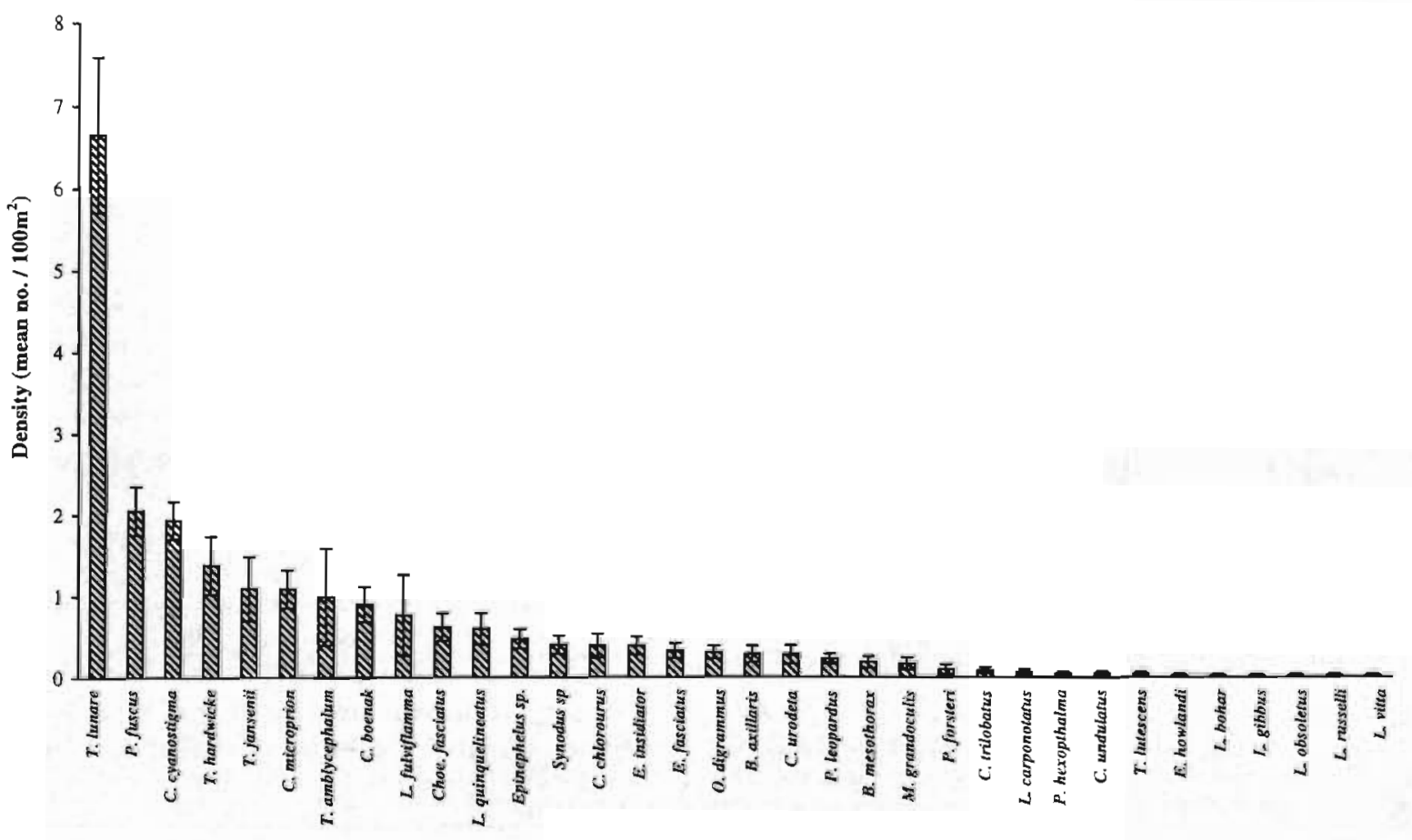

Fig. 4. Density (mean $\pm \mathrm{SE}$ ) of piscivorous species of fish at Lizard Island estimated by the combined census (cryptic speciesbaited point census; mobile species - quadrat census; $\mathrm{n}=54$ 


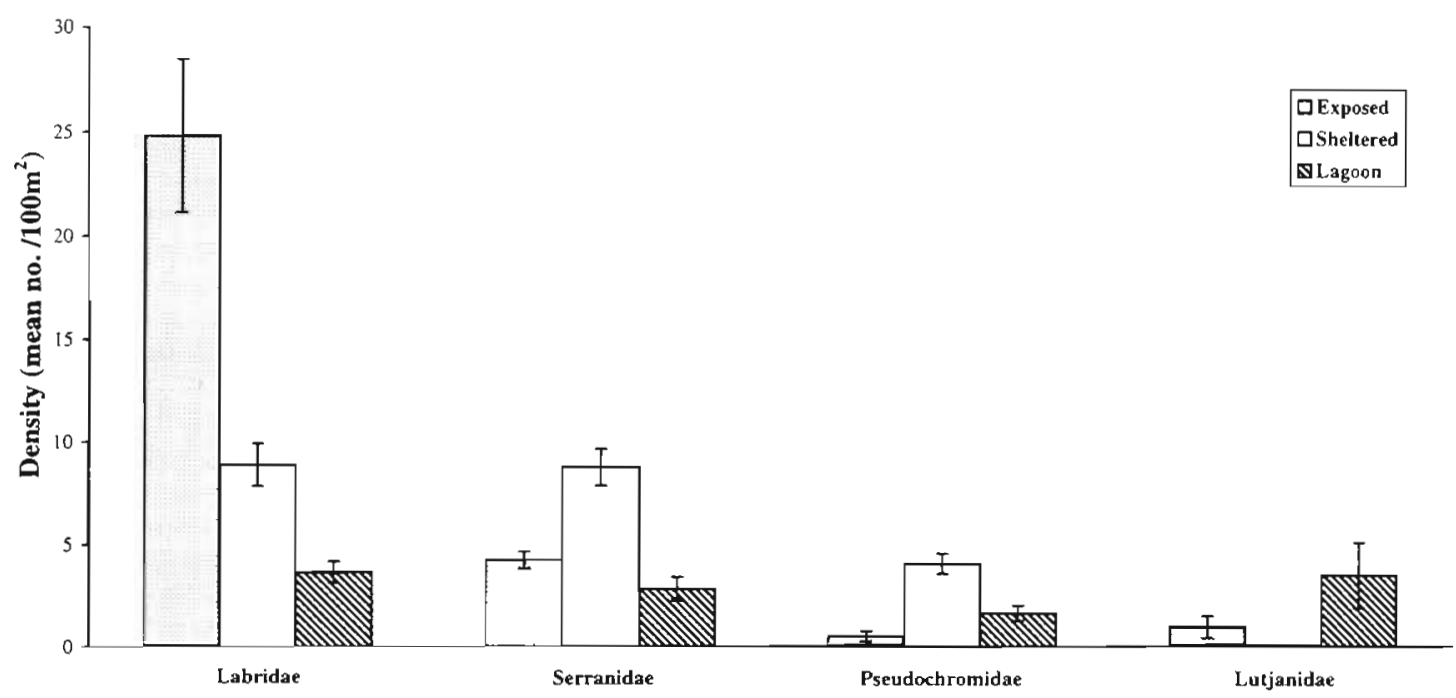

Fig. 5. Density (mean $\pm \mathrm{SE}$ ) of the 4 most common families of piscivorous fish in each of the 3 zones of exposure at Lizard Island (combined census; $\mathrm{n}=18$ per zone)

no significant variation in total numbers of piscivorous fish (Table 7).

\section{DISCUSSION}

The significantly higher piscivore densities estimated by the BPC were almost certainly due to the presence of bait within the census area. For the mobile species it was quite likely that many of the fish counted were attracted from outside the census area during the search period. This method is therefore only effective for measuring relative, rather than absolute, densities of mobile species. For the cryptic piscivorous species we censused, however, it is our argument that the difference between the $\mathrm{BPC}$ and $\mathrm{QC}$ density estimates

Table 5. (a) Results of nested ANOVAs examining spatial variation in total numbers of piscivorous fish belonging to the 4 most abundant families ('significant difference). (b) Results of Tukey's test (honestly significant difference method) showing significant differences in the mean density of families of piscivorous fish between the 3 zones of exposure (Exp $=$ exposed Shel $=$ sheltered, Lag = lagoon)

\begin{tabular}{|c|c|c|c|c|c|}
\hline $\begin{array}{l}\text { (a) ANOVAS } \\
\text { Source }\end{array}$ & SS & $d f$ & MS & $F$ & Significance of $F$ \\
\hline \multicolumn{6}{|l|}{ Labridae } \\
\hline Site (Zone) & 144.3 & 6 & 24.06 & 12.14 & $<0.001^{\circ}$ \\
\hline Zone & 295.8 & 2 & 147.9 & 6.15 & $0.035^{\circ}$ \\
\hline Error & 89.2 & 45 & 1.98 & & \\
\hline \multicolumn{6}{|l|}{ Serranidae } \\
\hline Site (Zone) & 27.84 & 6 & 4.64 & 3.71 & $0.004^{\circ}$ \\
\hline Zone & 62.71 & 2 & 31.35 & 6.76 & $0.029^{\circ}$ \\
\hline Error & 56.23 & 45 & 1.25 & & \\
\hline \multicolumn{6}{|l|}{ Pseudochromidae } \\
\hline Site (Zone) & 11.72 & 6 & 1.95 & 1.97 & 0.090 \\
\hline Zone & 63.11 & 2 & 31.55 & 16.15 & $0.004^{\circ}$ \\
\hline Error & 44.6 & 45 & 0.99 & & \\
\hline \multicolumn{6}{|l|}{ Lutjanidae } \\
\hline Site (Zone) & 40.45 & 6 & 6.74 & 3.19 & $0.011^{\circ}$ \\
\hline Zone & 38.37 & 2 & 19.18 & 2.85 & 0.135 \\
\hline Error & 95.16 & 45 & 2.11 & & \\
\hline \multicolumn{6}{|c|}{ (b) Tukey's HSD test } \\
\hline \multicolumn{2}{|l|}{ Family } & \multicolumn{2}{|c|}{ Result } & & \\
\hline Labridae & $\operatorname{Exp}>\operatorname{Lag}$ & & & & \\
\hline Serranidae & Shel $>$ Lag & & & & \\
\hline Pseudochromidae & Shel > Exp and Lag & & & & \\
\hline
\end{tabular}




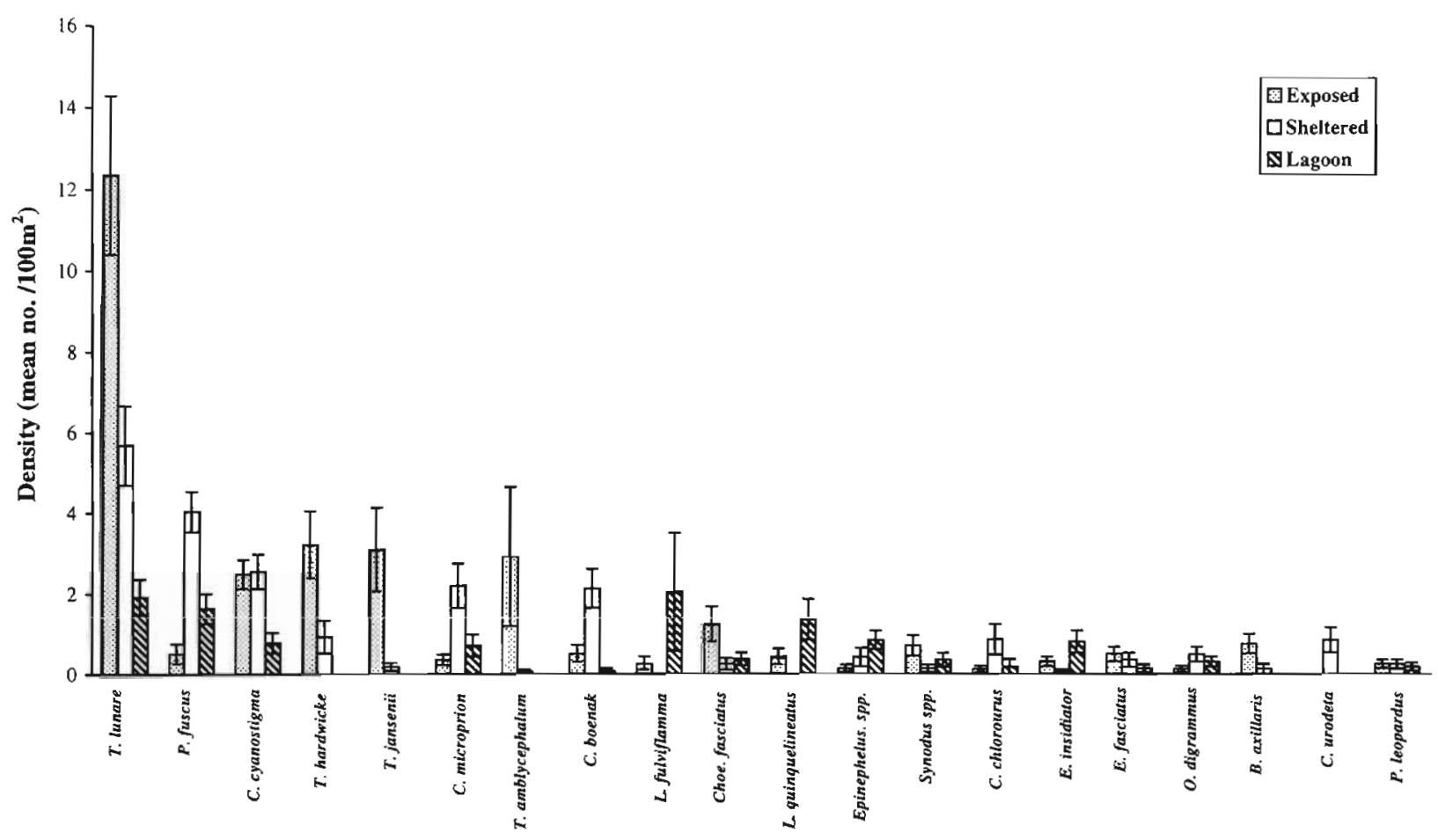

Fig. 6. Density (mean \pm SE) of the 20 most abundant species of piscivorous fish in each of the 3 zones of exposure at Lizard Island (combined census; $\mathrm{n}=18$ per zone)

was almost solely due to these fish being brought into view by the attraction of the bait and not by extra fish migrating into the census area.

The results from the patch reef experiment support the effectiveness of the BPC for the 3 rock-cod species, which were among the largest and most common cryptic species we censused, as in this case fish were not able to move in from outside the census areas. When compared to the tagging density estimates (our measure of absolute density), the baited census was found to be 85 to $96 \%$ accurate compared with 40 to $61 \%$ accurate when bait was not present. In addition, differences between the 2 techniques in the experiment were similar to those observed in the original censuses. Two of these rock-cod species, Cephalopholis cyanostigma and Cephalopholis boenak, are known to patrol relatively small and discrete home ranges and display intra and interspecific territoriality (Mackie 1993, Stewart 1998). Territorial defence mechanisms may reduce any potential immigration. The BPC can therefore be used as an effective technique for estimating the absolute density of these cryptic species. Most of the other cryptic species we counted (e.g. Pseudochromis fuscus, Paracirrhites forsteri, Cephalopholis urodeta, Epinephelus spp., E. fasciatus, E. corallicola and $E$. howlandi) were of similar size or even smaller than the rock-cods and are also thought to be quite sedentary (see Table 1). Hence it would seem unlikely that these species were migrating into the census areas. Consequently, we also argue that it was appropriate to use the BPC to estimate the density of these species.

This ability of the baited census technique to improve the accuracy of abundance estimates for cryptic species represents a significant advancement. In the past, such species have often been ignored in visual censuses as it was considered impossible to accurately estimate their abundance. The use of the BPC in this study showed that such species made up almost double the proportion of the piscivorous fish community than would have been indicated by traditional census methods. Previous studies may therefore have underestimated the abundance of cryptic piscivorous species. Our results place greater importance on the role of cryptic species in trophic dynamics.

Other research on the central Great Barrier Reef (Samoilys 1992), also suggests that traditional visual censuses are ineffective for estimating the density of cryptic piscivorous species. In her study, visual censuses underestimated the absolute density of cryptic serranids by more than 5 times when compared with explosive sampling. Although destructive sampling also has the potential to produce very accurate estimates of density for some cryptic fish species, the BPC technique offers several major advantages, Most importantly, it is non-destructive. Not only does this ensure minimal disturbance to the habitat and the 
Table 6. (a) Results of nested ANOVAs examining spatial variation in the abundance of the 20 most common species of piscivorous fish. Results are only shown for species which varied significantly. ('significant result). (b) Results of Tukey's test (HSD) showing significant differences in the mean density of species of piscivorous fish between the 3 zones of exposure

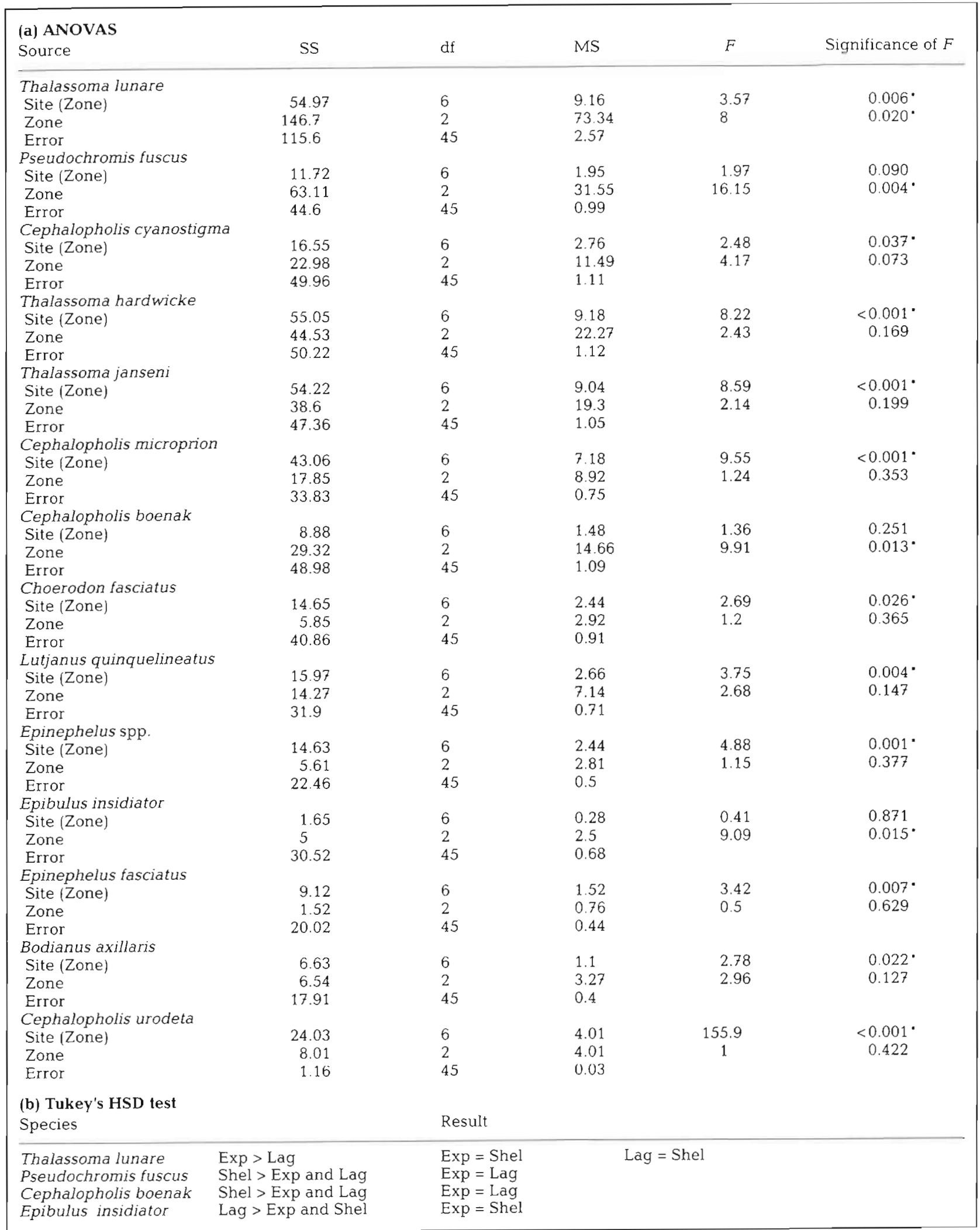



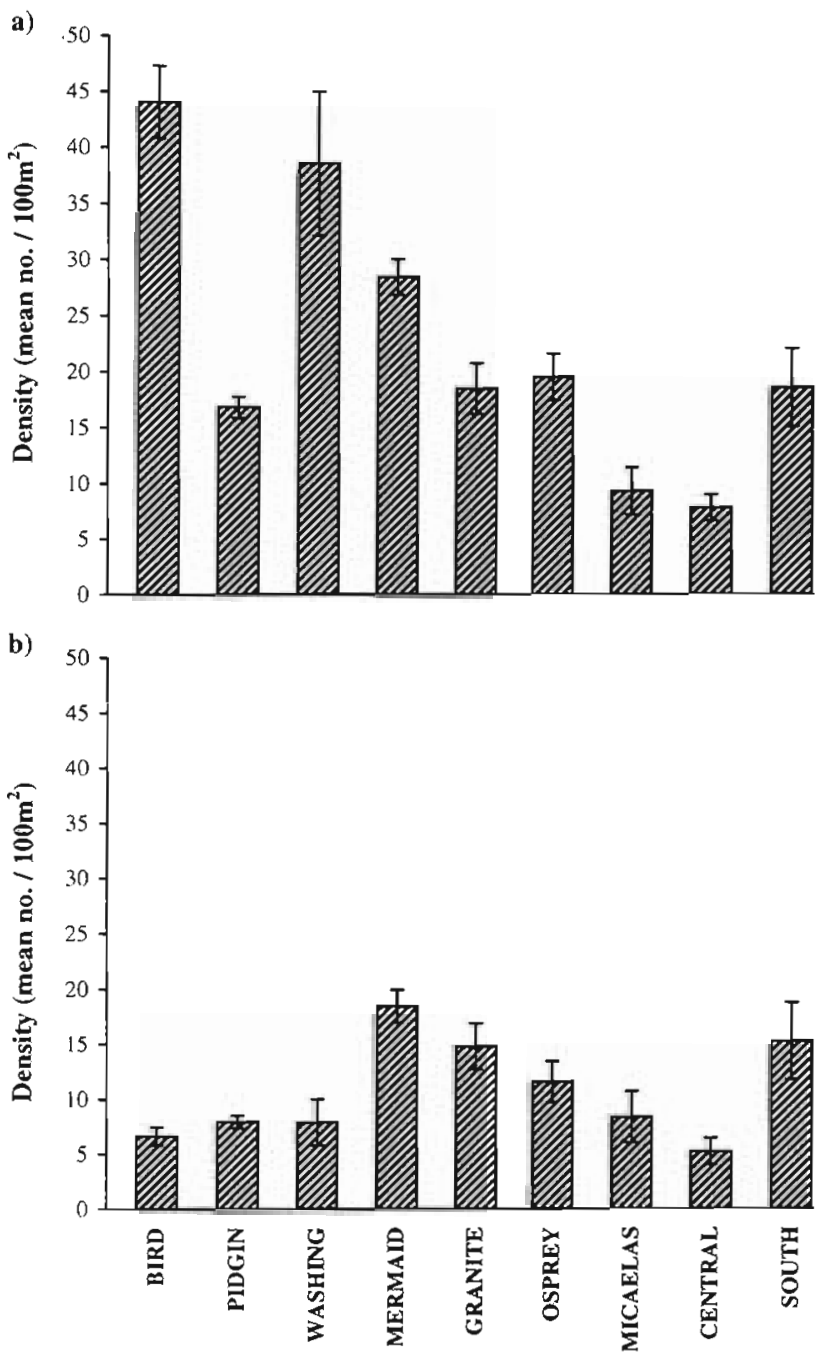

Fig. 7. Density (mean \pm SE) of the total number of piscivorous fish at each site censused at Lizard Island (combined census; $\mathrm{n}=6$ ); (a) all species; (b) confirmed piscivores only

community in question, but it also allows repeated censuses to be conducted in order to examine such factors as temporal variation in abundance or the effects of fishing. In addition, larger species of fish that are not effected by explosives are included in baited visual censuses. Tag and release programs such as used in this study may also provide accurate estimates of absolute density but are extremely labour intensive. In this case it took 2 people $7 \mathrm{~d}$ to tag only 3 species on 6 relatively small patch reefs.

One of the greatest benefits of the BPC may be for studying juvenile piscivores, as many piscivorous species are difficult to detect below a certain size (Eggleston 1995, Light \& Jones 1997). As a result the early life history of coral reef piscivores is poorly understood. This stage of the life history has proved to be of critical importance in other species because this is when mortality rates can be at their highest (Doherty \& Sale 1985, Eckert 1987). BPCs would bring juveniles out of their crevices so that abundances could be assessed and observations made over time. They could also assist in the capture of juveniles for tagging studies.

Of course the BPC does not solve all the problems of censusing cryptic coral reef fish. Some cryptic fish species (e.g. moray eels) may be very mobile and their abundance may therefore be overestimated by the BPC. Long-term, repeated use of BPCs in an area may also 'train' fish to respond to the bait and therefore cause the accuracy of the censuses to change over time. The magnitude of these problems requires further investigation.

For the more mobile, noncryptic species, previous work (e.g. Brock 1982, Thresher \& Gunn 1986, Samoilys 1992) suggests that traditional visual censuses are adequate. For example, Samoilys (1992) found that visual estimates were very similar to the results from explosives for roving serranids (e.g. Plectropomus leopardus) and lutjanids. These results justify combining QC estimates for mobile species with the BPC estimates for cryptic species in order to gain an accurate picture of piscivorous fish communities.

Based on the combined census, our study indicates that the piscivorous fish community at Lizard Island is dominated by small species belonging to the families Labridae, Serranidae and Pseudochromidae. This is in contrast to One Tree Island in the southern Great Barrier Reef where piscivorous fish below $20 \mathrm{~cm}$ in length

Table 7. Results of nested ANOVAs examining spatial variation in total numbers of piscivorous fish ("significant difference)

\begin{tabular}{|c|c|c|c|c|c|}
\hline Source & SS & $\mathrm{df}$ & MS & $F$ & Significance of $F$ \\
\hline \multicolumn{6}{|c|}{ (a) All species } \\
\hline Site (Zone) & 123.03 & 6 & 20.51 & 9.47 & $<0.001^{\circ}$ \\
\hline Zone & 169.63 & 2 & 84.81 & 4.14 & 0.074 \\
\hline Error & 97.41 & 45 & 2.17 & & \\
\hline \multicolumn{6}{|c|}{ (b) Confirmed piscivores only } \\
\hline Site (Zone) & 41.14 & 6 & 6.86 & 3.60 & $0.005^{\circ}$ \\
\hline Zone & 46.85 & 2 & 23.43 & 3.42 & 0.074 \\
\hline Error & 1211.72 & 45 & 26.93 & & \\
\hline
\end{tabular}


are uncommon (Connell \& Kingsford 1998). Several studies have indicated that small piscivorous coral reef fish prey heavily on newly recruited fish (Sweatman 1984, 1993, Martin 1994). In a recent study at Lizard Island by Beukers (1996), experimentally released new recruits of a damselfish, Pomacentrus moluccensis, were consumed exclusively by small piscivores such as Pseudochromis fuscus and Thalassoma lunare. Given the high abundance of small piscivores in the natural community at Lizard Island, mortality rates of newly settled fish could be higher there than at other areas such as One Tree Island. In support of this notion, this was exactly the pattern found by Caley (1995), when he compared fish communities on experimental patch reefs at the 2 locations.

The combined census also indicated considerable spatial variation in piscivore densities at both site and zonal level. Such variability could potentially translate to spatial variation in the mortality rates of prey fish and hence effect the distribution and abundance of these species. In support of this, both Aldenhoven (1986) and Beukers (1996) found spatial variation in the mortality rates of prey fish at Lizard Island. Connell (1996) linked mortality of a coral reef fish at One Tree Island with the abundance of predatory fish. The abundance of piscivorous species is not likely to be the sole factor effecting the impact of predators on prey fish, however. It is also necessary to have information on the availability of refuges for prey, the biomass of predators present and the degree of piscivory exhibited by these predators. Some of the species counted in this study, e.g. Synodus variegatus, are known to be almost $100 \%$ piscivorous (Sweatman 1984), while others such as Thalassoma lunare only occasionally consume fish (Randall et al. 1990, Martin 1994, Connell 1998). By restricting our analysis to confirmed piscivores (those species that normally consume fish) we observed different patterns in the abundance and distribution of piscivorous fish. Given that these species seem likely to have a greater impact on prey fish populations, it may be more meaningful to examine these patterns when investigating predator-prey relationships. Alternatively, although opportunistic piscivores may not consume many fish individually, due to their high abundance at Lizard Island (e.g. Thalassoma lunare) their combined impact on prey fish populations may be quite considerable (see also Parrish et al. 1986). A further understanding of this question can only be obtained by detailed diet analysis of the predatory species in question.

Spatial variation in the abundance and distribution of piscivorous coral reef fish has been reported in several other studies (e.g. Williams \& Hatcher 1983, Newman et al. 1997, Connell \& Kingsford 1998). Such spatial variation may be due to patterns of larval supply (Doherty 1981, Doherty \& Fowler 1994), habitat selection at the time of settlement (Williams 1991), post-settlement processes such as differential survival of recruits (Hixon 1991) or movement of piscivores to areas of optimal habitat and food supply (Robertson 1988, Lewis 1997). Given the potential role of piscivorous fish in influencing the community structure of prey fishes and the commercial and recreational importance of many piscivorous coral reef fish, further understanding of the factors controlling the distribution and abundance of these fish is a prime area for further research.

In summary, this study has shown that traditional visual census techniques may underestimate the abundance of cryptic fish in complex habitats such as coral reefs. The accuracy of these censuses, however, can be dramatically improved by using bait to attract cryptic species into view. The role of cryptic predatory fish in trophic dynamics, particularly their impact on populations and communities of prey fish, requires more attention. The baited census technique described here provides a useful tool for such research.

Acknowledgements. While carrying out this work B.D.S was supported by an Australian Postgraduate Research Award and J.S.B. was supported by an Overseas Postgraduate Research Scholarship. Fieldwork was funded by a Merit Research Grant to B.D.S. and an Australian Research Council grant to G. Jones. Many thanks to J. Ackerman, G. Jones, I. Keay, C. Ryan and C. Syms, who assisted in the field and again to $\mathrm{G}$. Jones for comments on the manuscript. Thanks also to N. Moltschaniwskyji for statistical advice. This is a contribution from the Lizard Island Research Station, a facility of the Australian Museum

\section{LITERATURE CITED}

Aldenhoven JM (1986) Local variation in mortality rates and life-expectancy estimates of the coral-reef fish Centropyge bicolor (Pisces: Pomacanthidae). Mar Biol 92: $237-244$

Beukers JS (1996) The relative roles of recruitment and postrecruitment processes in the regulation of a coral reef damselfish population. PhD thesis, James Cook University, Townsville

Brock RE (1982) A critique of the visual census method for assessing coral reef fish populations. Bull Mar Sci 32 $269-276$

Brock VE (1954) A preliminary report on a method of estimating reef fish populations. J Wildl Manage 18:297-308

Caley MJ (1993) Predation, recruitment and the dynamics of communities of coral reef fish. Mar Biol 117:33-43

Caley MJ (1995) Reef fish community structure and dynamics: an interaction between local and larger scale processes. Mar Ecol Prog Ser 129:19-29

Caley MJ, Carr MH, Hixon MA, Hughes TP, Jones GP, Menge BA (1996) Recruitment and the local dynamics of open marine populations. Annu Rev Ecol Syst 27:477-500

Connell SD (1996) Variations in mortality of a coral reef fish: links with predator abundance. Mar Biol 126:347-352

Connell SD (1998) Patterns of piscivory by resident predatory reef fish at One Tree Reef, Great Barrier Reef. Mar Freshw Res 49:25-30 
Connell SD, Kingsford MJ (1998) Spatial, temporal and habitat-related variation in the abundance of large predatory fish at One Tree Reef, Australia. Coral Reefs 17:49-57

Day RW, Quinn GP (1989) Comparison of treatments after analysis of variance in ecology. Ecol Monogr 59:433-463

Doherty PJ (1981) Coral reef fishes: recruitment-limited assemblages. Proc 4th Int Coral Reef Symp 2:465-470

Doherty P, Fowler A (1994) An empirical test of recruitmentlimitation in a coral reef fish. Science 263:935-939

Doherty PJ, Sale PF (1985) Predation on juvenile coral reef fishes: an exclusion experiment. Coral Reefs 4:225-234

Eckert GJ (1987) Estimates of adult and juvenile mortality for labrid fishes at One Tree Reef, Great Barrier Reef. Mar Biol 95:167-171

Eggleston DB (1995) Recruitment in Nassau groper Epinephelus striatus: post settlement abundance, microhabitat features, and ontogenetic habitat shifts. Mar Ecol Prog Ser 124:9-22

Gottleib M (1992) Utilization of habitat and food resources in a guild of wrasses (Labridae). BSc (Hons) thesis, James Cook University, Townsville

Gotshall DW (1987) The use of baited stations by divers to obtain fish relative abundance data. Calif Fish Game 73: $214-229$

Harmelin-Vivien ML, Bouchon C (1976) Feeding behaviour of some carnivorous fishes (Serranidae and Scorpaenidae) from Tulear (Madagascar). Mar Biol 37:329-340

Hiatt RW, Strasburg DW (1960) Ecological relationships of the fish fauna on coral reefs of the Marshall Islands. Ecol Monogr 30:65-127

Hixon MA (1991) Predation as a process structuring coral reef fish communities. In: Sale PF (ed) The ecology of fishes on coral reefs. Academic Press, New York, p 475-507

Hixon MA, Carr MH (1997) Synergistic predation, density dependence, and population regulation in marine fish. Science 277:946-949

Jones GP (1991) Post-recruitment processes in the ecology of coral reef fish populations: A multifactorial perspective. In: Sale PF (ed) The ecology of fishes on coral reefs. Academic Press, New York, p 294-328

Kingsford MJ (1992) Spatial and temporal variation in predation on reef fishes by coral trout (Plectropomus leopardus, Serranidae). Coral Reefs 11:193-198

Lewis AR (1997) Recruitment and post-recruitment immigration affect the local population size of coral reef fishes. Coral Reefs 16:139-149

Light PL, Jones GP (1997) Habitat preference in newly settled coral trout (Plectropomus leopardus, Serranidae). Coral Reefs 16:117-126

Mackie M (1993) Reproductive biology and social structure of the blue-spotted rock cod, Cephalopholis cyanostigma (Serranidae), and the effects of fishing. BSc (Hons) thesis, James Cook University, Townsville

Martin J (1994) Predation on juvenile coral-reef fish at Lizard Island, northern Great Barrier Reef: and ecological and

Editorial responsibility: Charles Birkehead (Contributing Editor), Mangilao, Guam behavioural study. BSc (Hons) thesis, James Cook University, Townsville

Meekan MG (1988) Settlement and mortality patterns of juvenile reef fishes at Lizard Island, northern Great Barrier Reef. Proc 6th Int Coral Reef Symp 2:779-784

Miles PS (1963) Seasonal and geographic variation in the diet of Lutjanus bohar (Forskal). MSc thesis, University of Hawaii, Honolulu

Newman SJ, Williams DMcB, Russ GR (1997) Patterns of zonation of assemblages of the Lutjanidae, Lethrinidae and Serranidae (Epinephelinae) within and among midshelf and outer-shelf reefs in the Great Barrier Reef. Mar Freshw Res 48:119-128

Parrish JD, Norris JE, Callahan MW, Callahan JK, Magarifuji EJ, Schroeder RE (1986) Piscivory in a coral reef fish community. Environ Biol Fishes 7:285-297

Randall JE, Brock VE (1960) Observations on the biology of Epinepheline and Lutjanid fishes of the Society Islands, with emphasis on food habits. Trans Am Fish Soc 89:9-16

Randall JE, Allen GR, Steene RC (1990) Fishes of the Great Barrier Reef and Coral Sea. Crawford House Press, Bathurst

Robertson DR (1988) Abundances of surgeonfishes on patchreefs in Caribbean Panama: due to settlement, or postsettlement events? Mar Biol 97:495-501

Sale PF, Douglas WA (1981) Precision and accuracy of visual census technique for fish assemblages on coral patch reefs. Environ Biol Fishes 6:333-339

Samoilys MA (1992) Review of the underwater visual census method developed by DPI/ACLAR project: visual assessment of reef fish stocks. Queensland Department of Primary Industries, Brisbane

Stewart BD (1998) Interactions between piscivorous coral reef fish and their prey. PhD thesis, James Cook University, Townsville

St John J (1995) Feeding ecology of the coral trout Plectropomus leopardus (Serranidae) on the Great Barrier Reef, Australia. PhD thesis, James Cook University, Townsville

Sweatman HPA (1984) A field study of the predatory behaviour and feeding rate of a piscivorous coral reef fish, the lizardfish Synodus englemani. Copeia 1984:187-194

Sweatman HPA (1993) A tropical snapper (Lutjanidae) that is piscivorous at settlement. Copeia 1993:1137-1139

Thresher RE, Gunn JS (1986) Comparative analysis of visual census techniques for highly mobile, reef associated piscivores (Carangidae). Environ Biol Fishes 17:93-116

Underwood AJ (1981) Techniques of analysis of variance in experimental marine biology and ecology. Oceanogr Mar Biol Annu Rev 19:513-605

Williams DMcB (1991) Patterns and processes in the distribution of coral reef fishes. In: Sale PF (ed) The ecology of fishes on coral reefs. Academic Press, London, $p$ 437-473

Williams DMcB, Hatcher AI (1983) Structure of fish communities on outer slopes of inshore, midshelf and outer shelf reefs of the Great Barrier Reef. Mar Ecol Prog Ser 10: $239-250$

Submitted: May 22, 1999; Accepted: November 2, 1999

Proofs received from author(s): April 3, 2000 